\title{
Long-Term Stable Supercontinuum Generation and Watt-level Transmission in Liquid Core Optical Fibers
}

\author{
Kay SChaARSChMidt, ${ }^{1,3, \dagger, *}$ HongWen XUAN, ${ }^{4,5, \dagger}$ Jens Kobelke, ${ }^{1}$ \\ Mario Chemnitz, ${ }^{1,3}$ Ingmar Hartl, ${ }^{5}$ Markus A. SChMidt, ${ }^{1,2,3}$ \\ ${ }^{1}$ Leibniz Institute of Photonic Technology, Albert-Einstein-Str. 9, 07745 Jena, Germany \\ ${ }^{2}$ Otto Schott Institute of Materials Research (OSIM), Friedrich-Schiller-University Jena, Fraunhoferstr. 6, 07743 Jena, Germany \\ ${ }^{3}$ Abbe Center of Photonics and Faculty of Physics, Friedrich-Schiller-University Jena, Max-Wien-Platz 1, 07743 Jena, Germany \\ ${ }^{4}$ Institut für Experimentalphysik, University of Hamburg, Luruper Chaussee 149, 22761, Hamburg \\ ${ }^{5}$ Deutsches Elektronen Synchrotron Hamburg (DESY), Notkestr. 85, 22607, Hamburg \\ *Corresponding author: kay.schaarschmidt@leibniz-ipht.de
}

(C) 2019 Optical Society of America - DOI: https://doi.org/10.1364/OL.44.002236

Due to their unique properties such as transparency, tunability, nonlinearity and dispersion flexibility, liquidcore fibers represent an important approach for future coherent mid-infrared light sources. However, the damage thresholds of those fibers are largely unexplored. Here, we report on the generation of solitonbased supercontinuum in carbon disulfide $\left(\mathrm{CS}_{2}\right)$ liquidcore fibers at average power levels as high as $0.5 \mathrm{~W}$ operating stable for a long term ( $>70$ hours) without any kind of degradation or damage. Additionally, we also show stable high power pulse transmission through liquid-core fibers exceeding $1 \mathrm{~W}$ of output average power for both $\mathrm{CS}_{2}$ and tetrachloroethylene $\left(\mathrm{C}_{2} \mathrm{Cl}_{4}\right)$ as core materials.

OCIS codes: (320.6629) Supercontinuum generation; (190.4370) Nonlinear optics, fibers; (060.2290) Fiber materials.

https://doi.org/10.1364/OL.44.002236

Optical fibers offer great flexibility in customizing the dispersion and the nonlinearity depending on the chosen fiber geometry and core material. Appropriate fiber designs give access to the anomalous dispersion (AD) domain with established laser technology. This allows generating and studying soliton-based supercontinuum generation (SCG). SCG relies on the fission of higher-order temporal solitons and the associated emission of dispersive waves - a sophisticated spectral broadening process that is particularly efficient in dispersion-tailored optical fibers (e.g. photonic crystal fibers). However, the possible bandwidth of the SCG process is limited by the transmission domains of fiber materials. Current research in nonlinear fiber optics investigates the incorporation of unconventional materials into a fiber geometry - so-called hybrid optical fibers [1] - to extend the spectral transmission region beyond the short-wave infrared (SWIR) towards the mid-infrared (MIR), which is highly relevant for numerous spectroscopic applications. For instance, hybrid optical fibers have outperformed silica fibers in many demonstrations of SCG in highly transparent core materials such as gasses [2,3], low-melting compound glasses (tellurites [4], chalcogenides [5,6], fluorides [7]), or even semiconductors (silicon [8,9], ZnO [10]). However, the mentioned examples either rely on sophisticated cladding microstructures to reduce losses to acceptable levels, or require complex fabrication methods. Clearly, more simple fiber geometries with comparable properties in transparency, optical and mechanical stability as well as their nonlinearity and dispersion tunability are highly favorable.

A platform that has recently attracted substantial attention and exhibits the mentioned properties are liquid-core optical fibers (LCFs). These fibers feature liquids as core materials and host unique opportunities for dispersion design. Inorganic solvents have been the focus of recent research in LCFs due to their high nonlinear refractive indices [11-13], their potentially high transparency at MIR wavelengths [14], their capability for realtime dispersion tuning via extraordinary high thermo-optical coefficients [15], and their noninstantaneous nonlinear response [11-13]. First SCG experiments using LCFs were reported in [1618], reaching wavelengths up to $2.4 \mu \mathrm{m}$ while average output power levels were limited to $<110 \mathrm{~mW}$. Recently, SCG in $\mathrm{CS}_{2}$-based $\mathrm{LCFs}$ in the AD regime suggests the generation of supercontinua (SC) with extraordinary high degrees of coherence at high soliton numbers due to a noninstantaneous phase contribution $[19,20]$. Moreover, carbon-chlorides are being investigated as future materials [21], too. The non-solid nature of the core suggests a high susceptibility of LCFs to high average input powers, i.e., high thermal loads, defining a demand for studying the long term stability and the power transmission capabilities of LCFs. In the present work we address these open issues by showing high average power SCG in $\mathrm{CS}_{2}$-based LCFs operating over several days without any degradation. Moreover, we show high average power transmission (output power $>1 \mathrm{~W}$ ) through $\mathrm{CS}_{2}$ and $\mathrm{C}_{2} \mathrm{Cl}_{4} \mathrm{LCFs}$ with remarkably low power fluctuations for long time scales. 

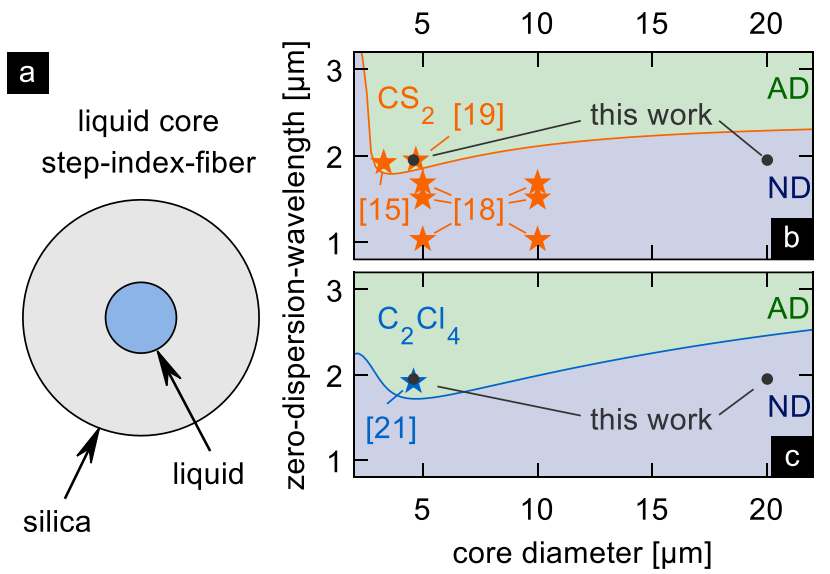

Fig. 1. (a) Schematic of a LCF (blue: liquid core, gray: glass cladding). The dependence of the zero dispersion wavelength on core diameter assuming (b) $\mathrm{CS}_{2}$ or (c) $\mathrm{C}_{2} \mathrm{Cl}_{4}$ as core materials (cladding: silica). Black dots indicate experiments conducted in this work, while stars refer to published works (orange: $\mathrm{CS}_{2}$, blue: $\mathrm{C}_{2} \mathrm{Cl}_{4}$ ). The colored backgrounds show $\mathrm{ND}$ (blue) and $\mathrm{AD}$ (green).

The LCFs used here consist of either $\mathrm{CS}_{2}$ or $\mathrm{C}_{2} \mathrm{Cl}_{4}$ filled into fibertype silica capillaries (Heraeus, Suprasil® F300) forming cylindrical step-index waveguides guiding light by total internal reflection (Fig. 1 (a)). For soliton-based SCG, the locations of the zero-dispersion wavelengths (ZDWs) are highly relevant and are plotted versus the inner core diameter (ID) for both solvents in Fig. 1 (b) and Fig. 1(c). The calculation relies on numerically solving the transcendental dispersion relation of ideal step-index fibers (dispersion of refractive index for $\mathrm{SiO}_{2}, \mathrm{CS}_{2}$ and $\mathrm{C}_{2} \mathrm{Cl}_{4}$ : [22], [19] and [21]). To access the $\mathrm{AD}$ domain at the Thulium laser wavelength around $2 \mu \mathrm{m}$, we selected ID $=4.6 \mu \mathrm{m}$, which yields a few mode fiber (number of modes for $\mathrm{CS}_{2}$ and $\mathrm{C}_{2} \mathrm{Cl}_{4}$ core: 7 and 4). More details, e.g., numerical aperture (NA), V-parameter, estimated modal attenuation $(\alpha)$, electronic nonlinear parameter $\gamma_{\mathrm{el}}$, and dispersion coefficients can be found in Table 1.

For high power transmission experiments we chose a geometry with large core (ID $=20 \mu \mathrm{m}$ ) to allow for high launching efficiency. In this case, the fiber supports $123(46)$ modes for $\mathrm{CS}_{2}\left(\mathrm{C}_{2} \mathrm{Cl}_{4}\right)$. The implementation of the LCFs relies on placing an empty capillary (sample length $15 \mathrm{~cm}$ ) in-between two optofluidic mounts that allow for simultaneous mode excitation and liquid filling (details can be found in [19]). After fixing the capillary appropriately, the input mount is filled with the respective solvent and the capillary fills via capillary action within minutes $[21,23]$. This procedure yields a mechanically stable and robust arrangement for external light coupling. To pump our nonlinear LCF we use a low-noise, mode-locked laser that provides highly stable pulse trains (design similar to [24], center wavelength: $1.95 \mu \mathrm{m}$, repetition rate: 380 $\mathrm{MHz}$, average power: $1.6 \mathrm{~W}$, pulse duration: $110 \mathrm{fs}$ ).

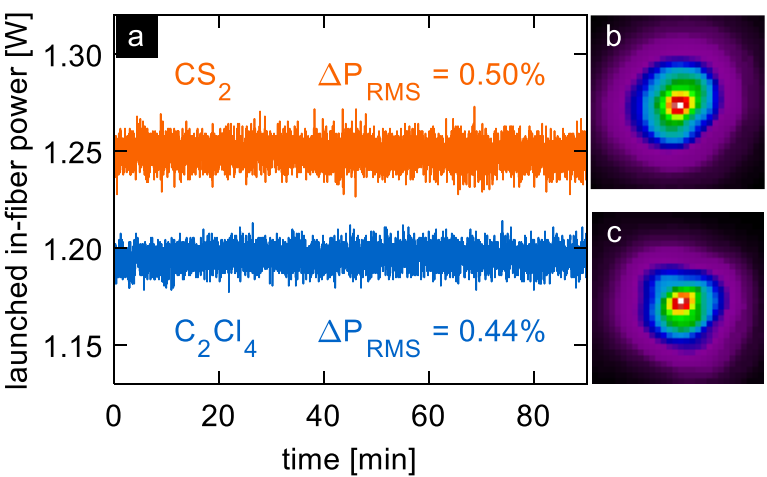

Fig. 2. Measured high power transmission (corrected for reflection and fiber loss, details in text) of $\mathrm{CS}_{2}$ (orange) and $\mathrm{C}_{2} \mathrm{Cl}_{4}$ (blue) LCFs (ID = $20 \mu \mathrm{m}$ ) for 90 minutes with low RMS noise (a). Output fiber mode at highest input power for $\mathrm{CS}_{2}$ (b) and $\mathrm{C}_{2} \mathrm{Cl}_{4}$ (c).

Optimal coupling efficiencies to LCFs were achieved with aspheric anti-reflection coated lenses at input $(\mathrm{f}=4.5 \mathrm{~mm}$, $\mathrm{NA}=0.55$ and $\mathrm{f}=7.5 \mathrm{~mm}, \mathrm{NA}=0.3)$ and output $(\mathrm{f}=6 \mathrm{~mm}$, $\mathrm{NA}=0.56$ ). Average powers were measured by a thermal power-head (Gentec) and, due to the large spectral bandwidth considered here, the spectral distributions of the transmitted light were recorded by two spectroscopic devices: (i) fiber coupled grating spectrum analyzer (ANDO, $0.6 \mu \mathrm{m}-1.7 \mu \mathrm{m}$ ) and (ii) free space coupled Fourier-transform spectrometer (Newport, $1.7 \mu \mathrm{m}-14 \mu \mathrm{m})$.

To reveal the power transmission capabilities of the fibers investigated, we prepared both $\mathrm{CS}_{2}-$ and $\mathrm{C}_{2} \mathrm{Cl}_{4}-\mathrm{LCFs}(\mathrm{ID}=20 \mu \mathrm{m}$ ) and measured the average output powers each second over up to two hours (Fig. 2 (a)). The chosen acquisition time frames are in accordance to previous stability analyses (see e.g., [7]). For both liquids we were able to obtain transmission levels up to $60 \%$ imposing coupling efficiencies above $70 \%$, considering reflection losses $(7 \%)$ at the air-sapphire interfaces and sample loss $(14.6 \%$ and $0.8 \%$ for $\mathrm{CS}_{2}$ and $\mathrm{C}_{2} \mathrm{Cl}_{4}$, respectively). Index gel was applied on the stripped fiber in a slight bend to ensure the measured power solely originates from the core. This method was confirmed by deliberately launching light in the cladding and observing the drop of power after the gel was applied.

Stable in-fiber power (corrected for $7 \%$ and attenuation) above one Watt with remarkably low relative RMS-fluctuation of $\approx 0.5 \%$ was achieved with good beam quality (see Fig. 2 (b) and Fig. 2 (c)), and no degradation was observed during the experiments. Our results were reproducible with different fiber samples employing the same geometry. To the best of our knowledge, this is the highest average power for ultrafast laser pulses transmitted through a neat $\mathrm{CS}_{2}$ and $\mathrm{C}_{2} \mathrm{Cl}_{4} \mathrm{LCF}$ reported so far. These findings in combination with the noteworthy results from [25], where $\mathrm{CCl}_{4}$ was shown to deliver $30 \mathrm{~mJ}, 200 \mathrm{~ns}$ pulses (corresponding to $150 \mathrm{~kW}$ of quasi-continuous wave average power within the pulse

Table 1: Relevant parameters for the SCG experiments (calculations refer to $\mathrm{HE}_{11}$ mode).

\begin{tabular}{cccccccccccc}
\hline core liquid & $\begin{array}{c}\lambda_{\text {pump }} \\
{[\mu \mathrm{m}]}\end{array}$ & $\begin{array}{c}\mathrm{ID} \\
{[\mu \mathrm{m}]}\end{array}$ & $\mathrm{NA}$ & $\mathrm{V}$ & $\begin{array}{c}\alpha \\
{[\mathrm{dB} / \mathrm{m}]}\end{array}$ & $\begin{array}{c}\mathrm{GVD} \\
{\left[\mathrm{ps}^{2} \mathrm{~km}^{-1}\right]}\end{array}$ & $\begin{array}{c}\mathrm{TOD} \\
{\left[\mathrm{ps}^{3} \mathrm{~km}^{-1}\right]}\end{array}$ & $\begin{array}{c}\mathrm{FOD} \\
{\left[\mathrm{ps}^{4} \mathrm{~km}^{-1}\right]}\end{array}$ & $\begin{array}{c}\mathrm{n}_{2, \mathrm{el}} \\
{\left[10^{-20} \mathrm{~m}^{2} / \mathrm{W}\right]}\end{array}$ & $\begin{array}{c}A_{\text {eff }} \\
{\left[\mu \mathrm{m}^{2}\right]}\end{array}$ & $\begin{array}{c}\gamma_{\text {el }} \\
{[1 / \mathrm{kWm}]}\end{array}$ \\
\hline $\mathrm{CS}_{2}$ & 1.95 & 4.6 & 0.66 & 7.6 & 4.23 & -22.2 & 0.386 & -0.01 & $15,[11]$ & 7.24 & 66.75 \\
\hline $\mathrm{C}_{2} \mathrm{Cl}_{4}$ & 1.95 & 4.6 & 0.38 & 4.2 & 0.23 & -22.3 & 0.223 & -0.01 & $5.5,[21]$ & 9.21 & 19.25 \\
\hline
\end{tabular}


duration) at a repetition rate of few $\mathrm{Hz}$, suggest further scalability of both output power and nonlinear interaction in experiments by increasing the pulse energy at high repetition rates.

The SCG experiments were performed in the AD domain of $\mathrm{CS}_{2}$ and $\mathrm{C}_{2} \mathrm{Cl}_{4} \mathrm{LCFs}$ with an ID of $4.6 \mu \mathrm{m}$ (Table 1, Figs. 1 (b) and (c)). It is important to note that the present configuration, with a laser pulse duration of $110 \mathrm{fs}$, imposes soliton dynamics that are mainly governed by the electronic response of the respective solvent [21], as reorientational molecular effects only dominate for significantly longer pulses $\left(\mathrm{CS}_{2}:>250 \mathrm{fs}\right.$ [19], $\mathrm{C}_{2} \mathrm{Cl}_{4}$ : $>500 \mathrm{fs}$ [21]). The experimentally measured power-spectral evolutions (Fig. 3) are acquired by increasing the input power in small steps and subsequently recording the respective spectrum. In each panel of Fig. 3 the data is interpolated for visualization and individually normalized to unity, as no spectral overlap between the OSA and FTIR spectrometers could be achieved due to high material absorption of the FTIR beam splitter. Both LCF samples show spectral broadening, i.e., clear indications of soliton fission up to $2.4 \mu \mathrm{m}$ and dispersive wave generation around $1.35 \mu \mathrm{m}$. The creation of the dispersive wave is substantially more pronounced in case of the $\mathrm{CS}_{2}$ sample, which can be attributed to the difference in third order dispersion (TOD) and in soliton number of the two configurations considered [26]. Extracting the fission energy from the point of first occurrence of the dispersive wave, both, the $\mathrm{CS}_{2}$ and $\mathrm{C}_{2} \mathrm{Cl}_{4}$ LCF exhibit fission for a soliton number of $N \approx 11$. Applying the phase matching condition from [26] to calculate the dispersive wave spectral position, good agreement is found in both cases $\left(\lambda_{\mathrm{DW}}=1.40 \mu \mathrm{m}\right.$ for $\mathrm{CS}_{2}$, and $\lambda_{\mathrm{DW}}=1.36 \mu \mathrm{m}$ for $\left.\mathrm{C}_{2} \mathrm{Cl}_{4}\right)$ assuming a higher order soliton at the pump wavelength $(1.95 \mu \mathrm{m})$. Another noteworthy feature of the two power-spectral evolutions is the difference in dispersive wave onset energies: In case of $\mathrm{CS}_{2}$, fission occurs at $E_{\mathrm{CS}_{2}}=0.47 \mathrm{~nJ}$ input pulse energy, whereas $E_{\mathrm{C}_{2} \mathrm{Cl}_{4}}=1.3 \mathrm{~nJ}$ for $\mathrm{C}_{2} \mathrm{Cl}_{4}$, which both are significantly lower compared to previous works employing longer pulses $[19,21]$. This difference in fission energy mainly originates from the different nonlinear coefficients $\left(\gamma_{\mathrm{CS}_{2}}=3.5 \cdot \gamma_{\mathrm{C}_{2} \mathrm{Cl}_{4}}\right)$ since the characteristic dispersion lengths, i.e., group velocity dispersions of both LCFs are very close $\left(\beta_{2}^{\mathrm{CS}_{2}} \approx \beta_{2}^{\mathrm{C}_{2} \mathrm{Cl}_{4}}\right)$. The ratio between the onset energies $K_{\mathrm{E}}=E_{\mathrm{CS}_{2}} / E_{\mathrm{C}_{2} \mathrm{Cl}_{4}}$ can be evaluated by the wellknown estimate for the fission length for peak power and considering that fiber length and fission length equal at the SC onset. This leads to $K_{\mathrm{E}}=\left(\gamma_{\mathrm{C}_{2} \mathrm{Cl}_{4}} \cdot \beta_{2}^{\mathrm{C}_{2} \mathrm{Cl}_{4}}\right) /\left(\gamma_{\mathrm{CS}_{2}} \cdot \beta_{2}^{\mathrm{CS}_{2}}\right)=0.29$ which agrees with the experimentally determined value of $K_{\mathrm{E}}=0.31$ (attenuation for $\mathrm{CS}_{2}$ included). Up to date, the results in Fig. 3 represent, to our best knowledge, the highest average power $\mathrm{SC}$ ever generated in a LCF.

The long-term stability of the generated SC was determined for the $\mathrm{CS}_{2}$ - $\mathrm{LCF}$ sample at maximum input conditions $\left(\mathrm{P}_{\mathrm{in}}=526 \mathrm{~mW}\right.$, $\mathrm{E}_{\mathrm{P}}=1.62 \mathrm{~nJ}, \mathrm{P}_{0}=14.75 \mathrm{~kW}, \mathrm{~N}=23.3$ ) by measuring the transmitted power (Fig. 4 (b)) and generated SC simultaneously (Fig. 4 (a)) for several days using an automated LabVIEW routine controlling an additional grating spectrometer (Ocean Optics, $1 \mu \mathrm{m}-2.6 \mu \mathrm{m}$ ) and the power-head. The average power was captured every second whereas the increment of the spectral acquisition was increased from one second at the beginning of the measurement - in order to capture potentially fast degradation - to a rate of one spectrum per minute. $\mathrm{A} \mathrm{CaF}_{2}$ window served as beam splitter to pick off $27 \%$ of the power for the spectrometer.

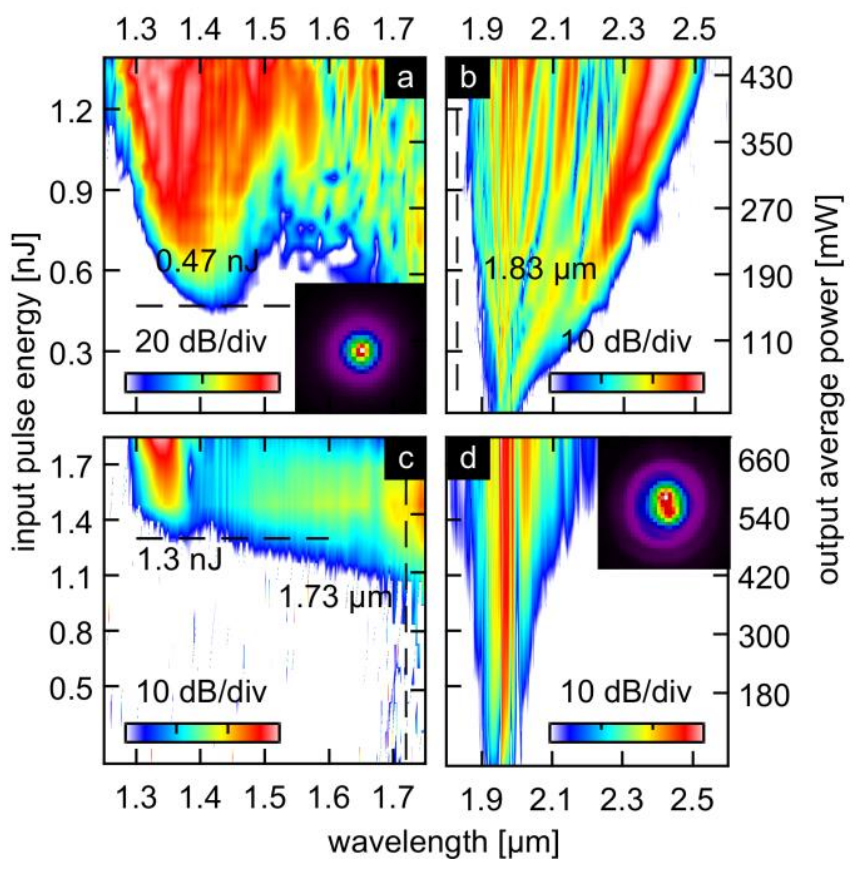

Fig. 3. Experimentally measured SCG in a $\mathrm{CS}_{2}((\mathrm{a})-(\mathrm{b}))$ and $\mathrm{C}_{2} \mathrm{Cl}_{4}((\mathrm{c})-$ (d)) filled LCF (ID $=4.6 \mu \mathrm{m})$. Spectra are normalized in each plot and interpolated. Left axes: input pulse energy (reflection and modal loss compensated), right axes: output power (reflection compensated). The respective ZDWs (fission energies) are indicated by the dashed vertical (horizontal) lines. The inset in (a) and (d) shows a typical mode profile.

The dynamic range of that spectrometer was not high enough to detect soliton and dispersive wave at the same time. However, since the dispersive wave is phase-matched to the fundamental soliton emerging during fission, fluctuations visible for the dispersive wave would also be present for that soliton, i.e., it is sufficient for a stability analysis to solely monitor the soliton side. Remarkably, all spectral features in the SWIR remain stable across the entire measurement duration (Fig. 4 (a)). This stability is also visible in the transmitted power measurements (Fig. 4(b)), showing no indication of degradation. The slow decay of the transmission over the course of many hours (i.e., the negative slope of the curves in Fig. 4 (b)) results solely from changing in-coupling conditions, since the initial transmission level could be fully recovered by re-adjusting the coupling, which is indicated by the kink in the black curve in the inset of Fig. 4 (b) occurring after 45 hours. Both high average output power and long term stability of the spectrum are essential for many light sources designed for real-world applications.

In this work, we revealed the power resilience and the stability of ultrafast SC generation in LCFs. Specifically, we showed that $\mathrm{CS}_{2-}$ and $\mathrm{C}_{2} \mathrm{Cl}_{4}$-filled LCFs (ID $\left.=20 \mu \mathrm{m}\right)$ allow transmitting high average powers of more than $1 \mathrm{~W}$ measured at the output. Furthermore, we demonstrated soliton-based SCG spanning from $1.3 \mu \mathrm{m}$ to $2.5 \mu \mathrm{m}$ at record-high average output power levels $(480 \mathrm{~mW}$ for $\mathrm{CS}_{2}$ and $650 \mathrm{~mW}$ for $\mathrm{C}_{2} \mathrm{Cl}_{4}$ ) for dispersion optimized $\mathrm{CS}_{2}$ and $\mathrm{C}_{2} \mathrm{Cl}_{4}$ LCFs. The stability of the SC was monitored over days for the $\mathrm{CS}_{2}-$ sample, showing no indication of any kind of degradation over more than 70 hours of nonstop pulsed exposure at an average input power of $1.6 \mathrm{~W}$.

Our results clearly highlight inorganic LCFs, incorporating $\mathrm{CS}_{2}$ 


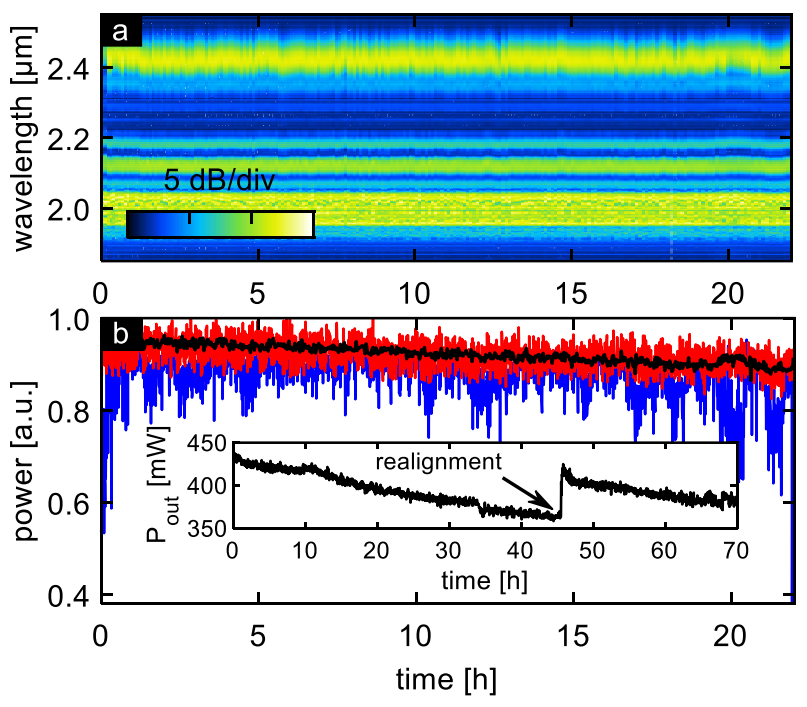

Fig. 4. Long-term stability measurement of SCG in a $\mathrm{CS}_{2}$ filled LCF (ID = $4.6 \mu \mathrm{m}$ ). (a) Spectral distribution of the soliton side of the generated SC measured with the grating spectrometer. (b) Normalized power after the fiber (black, measured by a thermal power meter) and normalized integrated spectral windows for two selected intervals (red: transmitted pump light $(1.9 \mu \mathrm{m}-2.0 \mu \mathrm{m})$, blue: soliton range $(2.3 \mu \mathrm{m}-$ $2.6 \mu \mathrm{m})$ ). The inset shows the entire time interval of the measurements. The slope of the curves in (b) results from beam drift reducing incoupling which was compensated after $45 \mathrm{~h}$.

and $\mathrm{C}_{2} \mathrm{Cl}_{4}$ as core media, as robust platforms for high average power transmission and nonlinear light generation, which is against the common believe that LCFs are highly susceptible to high average photon flux. Previous works on $\mathrm{CS}_{2} \mathrm{LCF}$ showed damage thresholds below $90 \mathrm{~mW}$ at pulse energies of $15 \mathrm{~nJ}$ for $460 \mathrm{fs}$ pulses at a repetition rate of $5.6 \mathrm{MHz}$ [19], which is likely to be caused by non-thermal processes such as molecular dissociation due to high irradiance, whereas in [17] $200 \mathrm{~mW}$ of continuous average power at comparable wavelengths and LCF design were reported without damage. Therefore, our study suggests that LCFs infiltrated with inorganic solvents enable handling of even higher amounts of average power, as long as certain pulse energy is not exceeded.

This could yield a performance comparable to soft glass fibers, where MIR SCG was demonstrated at multi-Watt level for ZBLAN fibers $[27,28]$. However, only chalcogenide glasses offer full access to the fingerprint spectral region beyond $6 \mu \mathrm{m}$ [29] at comparably low damage thresholds. With potential transmission bands exceeding those of ZBLAN, telluride- and fluoride-based fibers, inorganic solvent filled LCFs promise to become a true alternative to soft glass fibers in the future. The combination of the measured stability, sophisticated nonlinearity, real-time dispersion tunability, and potential MIR transparency makes LCFs highly relevant for both fundamental sciences, as well as for applications that demand high photon flux at difficult-to-access spectral domains. Since the available laser power was limited in our experiments to $1.6 \mathrm{~W}$, we expect further scalability, as higher pulse energies could be transmitted in previous experiments [19].

Funding. Deutsche Forschungsgemeinschaft (DFG) (IRTG 2101, SCHM2655/3-1 SCHM2655/11-1, SCHM2655/12-1); Gordon and Betty Moore Foundation (Grant GBMF4744);
These authors contributed equally to this work.

\section{References}

1. M. A. Schmidt, A. Argyros, and F. Sorin, Adv. Opt. Mater. 4, 13 (2016).

2. P. S. J. Russell, P. Hölzer, W. Chang, A. Abdolvand, and J. C. Travers, Nat. Photonics 8, 278 (2014).

3. R. Sollapur, D. Kartashov, M. Zürch, A. Hoffmann, T. Grigorova, G. Sauer, A. Hartung, A. Schwuchow, J. Bierlich, J. Kobelke, M. Chemnitz, M. A. Schmidt, and C. Spielmann, Light Sci. Appl. 6, e17124 (2017).

4. H. Ebendorff-Heidepriem, K. Kuan, M. R. Oermann, K. Knight, and T. M. Monro, Opt. Mater. Express 2, 432 (2012).

5. S. Xie, F. Tani, J. C. Travers, P. Uebel, C. Caillaud, J. Troles, M. A. Schmidt, and P. S. J. Russell, Opt. Lett. 39, 5216 (2014).

6. K. F. Lee, N. Granzow, M. A. Schmidt, W. Chang, L. Wang, Q. Coulombier, J. Troles, N. Leindecker, K. L. Vodopyanov, P. G. Schunemann, M. E. Fermann, P. S. J. Russell, and I. Hartl, Opt. Lett. 39, 2056 (2014).

7. X. Jiang, N. Y. Joly, M. A. Finger, F. Babic, G. K. L. Wong, J. C. Travers, and P. S. J. Russell, Nat. Photonics 9, 133 (2015).

8. L. Shen, N. Healy, L. Xu, H. Y. Cheng, T. D. Day, J. H. V Price, J. V Badding, and A. C. Peacock, Opt. Lett. 39, 5721 (2014).

9. J. Ballato, T. Hawkins, P. Foy, R. Stolen, B. Kokuoz, M. Ellison, C. McMillen, J. Reppert, A. M. Rao, M. Daw, S. R. Sharma, R. Shori, O. Stafsudd, R. R. Rice, and D. R. Powers, Opt. Express 16, 18675 (2008).

10. J. R. Sparks, R. He, N. Healy, M. Krishnamurthi, A. C. Peacock, P. J. A. Sazio, V. Gopalan, and J. V. Badding, Adv. Mater. 23, 1647 (2011).

11. M. Reichert, H. Hu, M. R. Ferdinandus, M. Seidel, P. Zhao, T. R. Ensley, D. Peceli, J. M. Reed, D. A. Fishman, S. Webster, D. J. Hagan, and E. W. Van Stryland, Optica 3, 657 (2016).

12. P. Zhao, M. Reichert, S. Benis, D. J. Hagan, and E. W. Van Stryland, Optica 5, 583 (2018).

13. M. L. Miguez, T. G. B. De Souza, E. C. Barbano, S. C. Zilio, and L. Misoguti, Opt. Express 25, 3553 (2017).

14. M. J. Weber, Handbook of Optical Materials (CRC Press, 2003).

15. M. Chemnitz, R. Scheibinger, C. Gaida, M. Gebhardt, F. Stutzki, S. Pumpe, J. Kobelke, A. Tünnermann, J. Limpert, and M. A. Schmidt, Optica 5, 695 (2018).

16. M. Vieweg, T. Gissibl, S. Pricking, B. T. Kuhlmey, D. C. Wu, B. J. Eggleton, and H. Giessen, Opt. Express 18, 25232 (2010).

17. D. Churin, T. N. Nguyen, K. Kieu, R. A. Norwood, and N. Peyghambarian, Opt. Mater. Express 3, 1358 (2013).

18. S. Kedenburg, T. Gissibl, T. Steinle, A. Steinmann, and H. Giessen, Opt. Express 23, 8281 (2015).

19. M. Chemnitz, M. Gebhardt, C. Gaida, F. Stutzki, J. Kobelke, J. Limpert, A. Tünnermann, and M. A. Schmidt, Nat. Commun. 8, 42 (2017).

20. R. Vasantha Jayakantha Raja, A. Husakou, J. Hermann, and K. Porsezian, J. Opt. Soc. Am. B 27, 1763 (2010).

21. M. Chemnitz, C. Gaida, M. Gebhardt, F. Stutzki, J. Kobelke, A.

Tünnermann, J. Limpert, and M. A. Schmidt, Opt. Express 26, 3221 (2018).

22. I. H. Malitson, J. Opt. Soc. Am. 55, 1205 (1965).

23. E. W. Washburn, Phys. Rev. 17, 273 (1921).

24. J. Jiang, C. Mohr, J. Bethge, A. Mills, W. Mefford, I. Hartl, M. E. Fermann, C.-C. Lee, S. Suzuki, T. R. Schibli, N. Leindecker, K. L. Vodopyanov, and P. G. Schunemann, in Conference on Lasers and Electro-Optics 2012 (OSA, 2012), p. CTh5D.7.

25. S. Diemer, J. Meister, R. Jung, S. Klein, M. Haisch, W. Fuss, and P. Hering, Appl. Opt. 36, 9075 (1997).

26. S. Roy, S. K. Bhadra, and G. P. Agrawal, Phys. Rev. A 79, 023824 (2009). 27. K. Liu, J. Liu, H. Shi, F. Tan, and P. Wang, Opt. Express 22, 24384 (2014).

28. J. Swiderski, M. Michalska, and P. Grzes, Appl. Phys. B 124, 152 (2018).

29. C. R. Petersen, U. Møller, I. Kubat, B. Zhou, S. Dupont, J. Ramsay, T. Benson, S. Sujecki, N. Abdel-Moneim, Z. Tang, D. Furniss, A. Seddon, and O. Bang, Nat. Photonics 8, 830 (2014) 